\title{
A 19-year-old patient with atypical chronic myeloid leukemia
}

\section{Philipp Ernst ${ }^{1}$ - Björn Engmann ${ }^{2}$. Jochen J. Frietsch ${ }^{1}$. Ulf Schnetzke ${ }^{1} \cdot$ Sebastian Scholl ${ }^{1} \cdot$ Bernhard Theis $^{3}$. Hans H. Kreipe ${ }^{4}$. Thomas Ernst ${ }^{1} \cdot$ Anita Glaser $^{5}$ - Torsten Haferlach ${ }^{6} \cdot$ Thilo Koch $^{2}$ • Andreas Hochhaus ${ }^{1}$. Inken Hilgendorf ${ }^{1}$}

Received: 25 February 2020 / Accepted: 10 March 2020 / Published online: 19 March 2020

(C) The Author(s) 2020

Dear Editor,

Atypical chronic myeloid leukemia (aCML) is a rare, aggressive myeloproliferative disorder. The outcome of patients is poor and the therapeutic options are limited. We present the case of a 19-year-old male adolescent who initially had acute abdominal pain due to leukostatic ischemic colitis.

A 19-year-old male patient presented to our emergency department with fever, sudden painful abdominal cramps, and bilious vomiting. Computed tomography revealed severe right-sided colitis and a massive hepatosplenomegaly. Furthermore, increased leukocytes $106 / \mathrm{nL}$ and platelets $1250 / \mathrm{nL}$ as well as a mild anemia were detected. The differential blood count showed $41 \%$ segment pithy granulocytes, $15 \%$ rod pithy granulocytes, $5 \%$ metamyelocytes, $23 \%$ myelocytes, $2 \%$ promyelocytes, $4 \%$ blasts, $1 \%$ basophilic granulocytes, $1 \%$ eosinophilic granulocytes, and $4 \%$ erythroblasts (Fig. 1a). Cytological examination of the bone marrow (BM) showed hypercellularity with an increased and dysplastic granulopoiesis and megakaryopoiesis as well as a relatively diminished and also dysplastic erythropoiesis (Fig. 1b, c). The proportion of non-erythroid blasts was $10 \%$. Histological findings showed an almost complete disappearance of adipose

Philipp Ernst

philipp.ernst@med.uni-jena.de

1 Abteilung Hämatologie und Internistische Onkologie, Klinik für Innere Medizin II, Universitätsklinikum Jena, Am Klinikum 1, 07740 Jena, Germany

2 Klinik für Innere Medizin, Burgenlandkreis Klinikum, Naumburg, Germany

3 Institut für Pathologie, Universitätsklinikum Jena, Jena, Germany

4 Institut für Pathologie, Medizinische Hochschule Hannover, Hannover, Germany

5 Institut für Humangenetik, Universitätsklinikum Jena, Jena, Germany

6 MLL Münchner Leukämielabor, Munich, Germany tissue due to myeloproliferation. The increased granulopoiesis still preserved maturation without involvement of the eosinophil series. Signs of dysplasia in megakaryopoiesis were detectable without finding micromegakaryocytes (Fig. 1d). Cytogenetic analysis by fluorescence in situ hybridization (FISH) failed to detect $B C R-A B L 1$ gene fusion or FGFR1 rearrangements but did find a trisomy $8(47, \mathrm{XY},+8)$. Moleculargenetic analysis excluded mutations for $B C R$ ABL1, JAK2, CALR, MPL, ASXL1, CBL, CSFR3, ETNK1, $E Z H 2, S E T B P 1$, and TET2. However, mutations were found in the genes $S F 3 B 1$ and NF1.

Based on the evidence of an as yet unidentified myeloproliferative disease and the suspected colitis associated with it, oral cytoreductive therapy was started at $1 \mathrm{~g}$ hydroxyurea daily. In terms of differential diagnosis, it was suspected that the patient was suffering from a $B C R-A B L 1$ negative myeloproliferative/myelodysplastic disease. In contrast to $B C R-A B L 1$ positive $C M L$, the absence of $B C R-A B L 1$ transcript as well as multilinear dysplasia with prominent dysgranulopoiesis and the absence of basophilia were conspicuous. Since leukocytosis with more than $10 \%$ granulocytic precursors, hypercellular BM, and less than $20 \%$ blasts in peripheral blood and BM were also detectable, the patient met the criteria for aCML according to the 2016 WHO classification.

Two days after hospitalization, he developed a septic condition with clinical suspicion of an acute abdomen. Due to a diffuse peritonitis and a suspected perforation of the right hemicolon, an emergency hemicolectomy on the right was performed. Severe edematous bowel wall with ulcerous mucosal defects and inflammatory infiltrates of the mucosa (Fig. 2a, b), thrombosis of the submucosal capillaries, and fibrinouspurulent inflammation of the serosa corresponding to ischemic colitis with peritonitis appeared histologically (Fig. 2c, d).

In addition to hydroxyurea, cytoreductive therapy with cytarabine $100 \mathrm{mg} / \mathrm{m}^{2}$ daily was supplemented for 3 days at 4-week intervals for 3 months resulting in partial remission. Five months after diagnosis, the patient received an allogeneic hematopoietic blood stem cell transplantation (HSCT) from a 

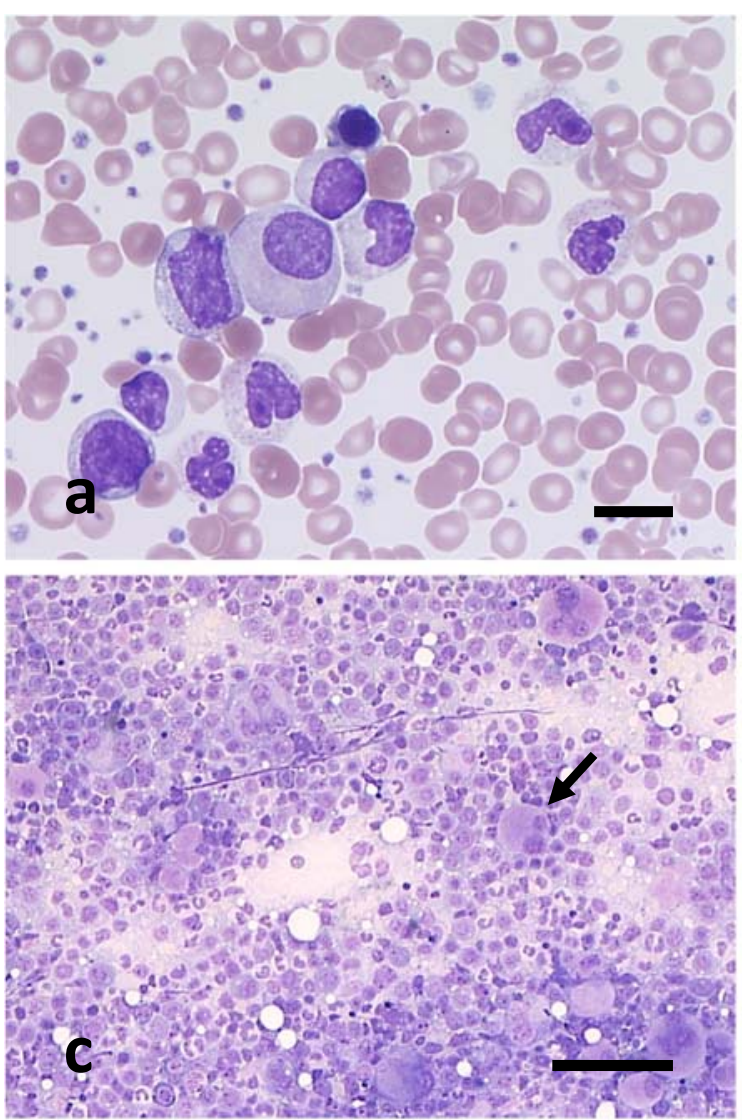

Fig. 1 Pappenheim staining of blood smear (a) and BM smears (b, c) and Giemsa staining of pelvic crest trepanation (d) at the first presentation in our hospital. The peripheral blood shows leukocytosis with left-shifted maturing granulopoiesis and a marked thrombocytosis (a). Dysplastic

9/10 HLA-mismatched unrelated donor. Due to poor general condition with pulmonary aspergillosis, gluteal infection, immobility, and renal impairment, he received a reduced toxicity conditioning with cytarabine, treosulfan, and fludarabine. On day +29 , the BM showed a regenerating hematopoiesis and a chimerism of $82 \%$. Furthermore, in about $20-35 \%$ of interphases, the clone specific trisomy 8 could be detected by FISH. Therefore, the immunosuppressive therapy was rapidly reduced so that no trisomy 8 and a donor proportion of $100 \%$ could be achieved on day +55 (Fig. 3 ).

However, 6 months after HSCT, a cytogenetic recurrence and 1 month later, a hematological recurrence were detected, despite discontinuation of immunosuppression. Therapy with hydroxyurea was started again. Subsequently, three donor lymphocyte infusions (DLI, $5 \times 10^{6}, 1 \times 10^{7}$, and $1.7 \times 10^{7}$ CD3-positive cells/kg bwt, respectively) were performed to enhance the graft-versus-leukemia $(\mathrm{GvL})$ effect. Despite relapse, the general condition improved and the patient had fully regenerated renal function. Therefore, a second allogeneic HSCT was planned. However, on day +409 , he presented again with progressive pains due to displacing growth of his spleen. Intravenous cytarabine $\left(100 \mathrm{mg} / \mathrm{m}^{2}\right.$ for 3 days $)$ was
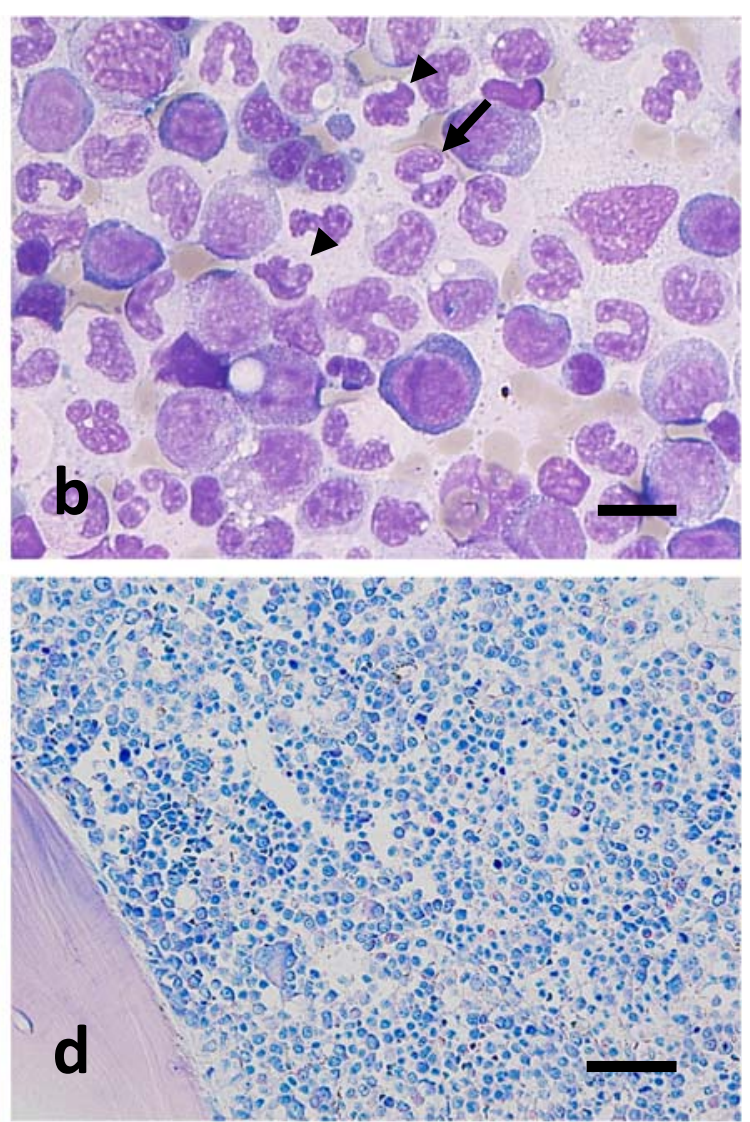

changes such as pseudo-Pelger forms (arrow in $\mathbf{b}$ ), chromatin clumping (arrowheads in b), hypogranulation, and atypical megakaryocytes (arrow in $\mathbf{c})$ can be found in the BM. Scale bars $=10 \mu \mathrm{m}(\mathbf{a}, \mathbf{b}), 50 \mu \mathrm{m}(\mathbf{c}, \mathbf{d})$

administered as differential leukocyte count revealed an excessive increase in immature cells. Unfortunately, the patient deceased within 3 days (on day +416 ) on relapse with septic shock, disseminated intravascular coagulation, and multiorgan failure.

Due to the aggressive biology of the disease as in this case, the aim is to HLA-typify aCML patients for allogeneic HSCT as early as possible. If they are suitable for HSCT and if no cytoreduction is initially necessary, it is possible to proceed directly to HSCT if a donor is available. However, in most cases, cytoreductive therapy is required. Therefore, hypomethylating therapy as well as pegylated interferon $\alpha$ or hydroxyurea is recommended prior to transplantation when the aCML clones have an inconspicuous mutation status [1]. If potentially actionable, myeloid mutations are detectable (JAK2, CSF3R, RAS); therapy with a targeted agent is an option. In contrast to $B C R-A B L 1$ positive CML, however, no selective targeted therapy with tyrosine kinase inhibitors is available. Due to the patient's hyperleukocytosis with associated ischemic colitis, cytoreductive therapy was initially necessary, and because the worsened overall condition, including the surgical formation of a terminal ileostomy and pulmonary and soft tissue infections, no timely 

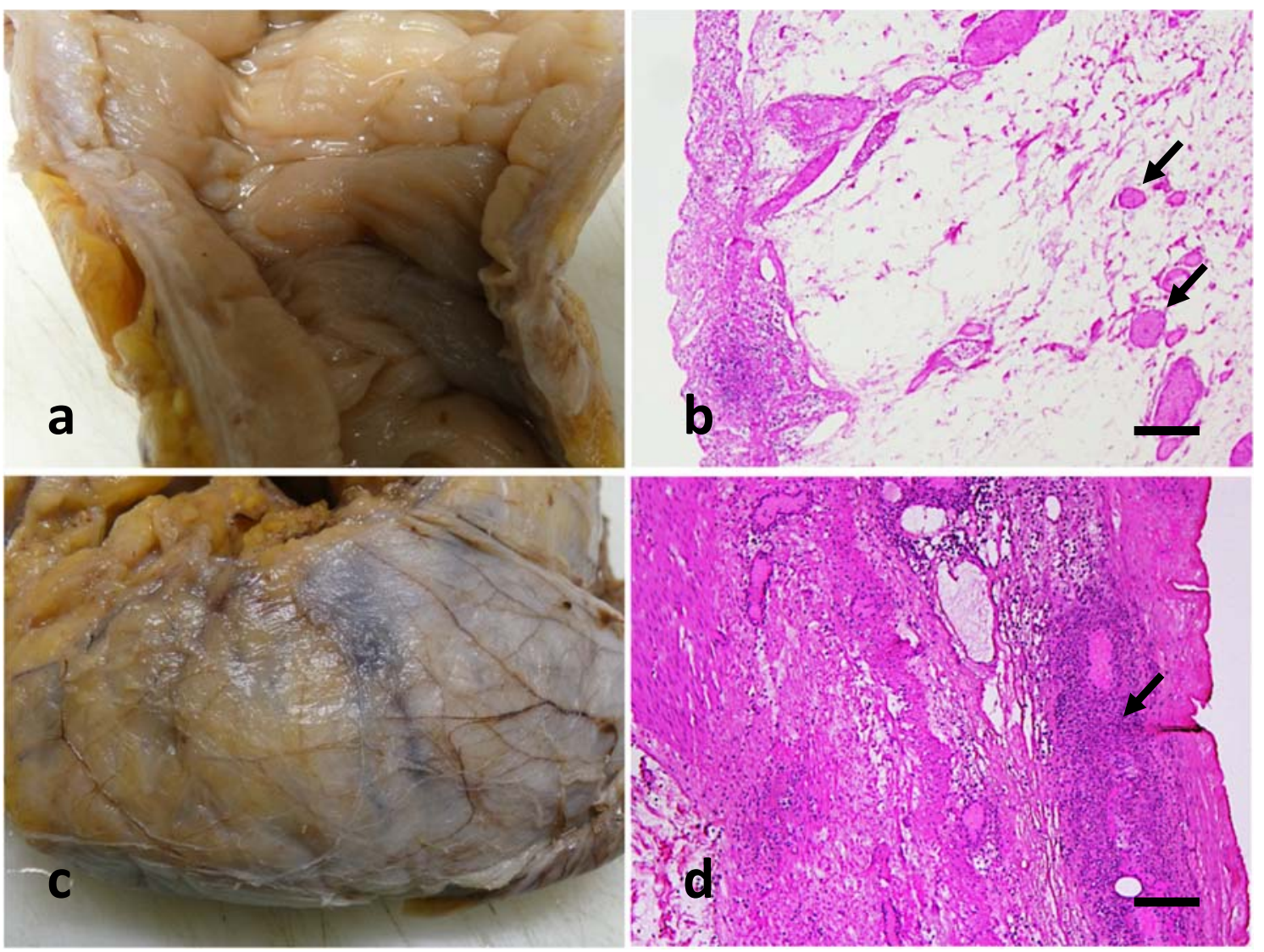

Fig. 2 Preparation after right hemicolectomy (a, c) and HE staining of histological sections of the colonic wall (mucosa left in $\mathbf{b}$, serosa right in d). The mucosa shows a strong edematous wall thickening (a) as well as a complete necrosis with inflammatory infiltrates, strongly edematous and widened submucosa and capillary thrombi (arrows in b). In the serosa,

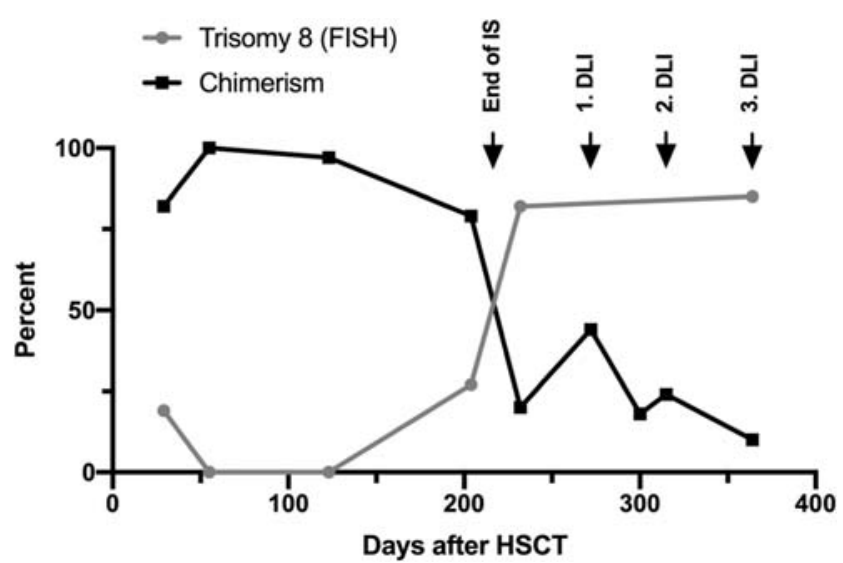

Fig. 3 History of chimerism (percentage of donor cells) and FISH detectable cells with trisomy 8 (percentage of all BM cells) after hematopoietic blood stem cell transplantation (HSCT). After initial reduction of immunosuppression (IS) on day +29 , a chimerism of $100 \%$ could be achieved. After another drop in chimerism and increase in trisomy 8 content from day +204 , IS was rapidly stopped on day + 217. Due to the inadequate graft-versus-leukemia (GvL) effect, the patient received donor lymphocytes infusions (DLI) on day +272 , + 315 , and $+364\left(5 \times 10^{6}, 1 \times 10^{7}\right.$, and $1.7 \times 10^{7} \mathrm{CD} 3$-positive cells $/ \mathrm{kg}$ bwt, respectively) with only moderate success there is an inflammation-related fibrosis (c) and the entire intestinal wall is interspersed with a florid inflammatory infiltrate (here predominantly neutrophilic granulocytes in the area of subserosa and serosa) (arrow in d). Scale bars $=200 \mu \mathrm{m}$

HSCT was possible. The time from diagnosis to HSCT was 6 months; the EBMT risk score was 2 points (HLA-compatible unrelated donor, accelerated phase before transplantation) and the HCT-CI 4 points (mild hepatic and pulmonary comorbidity, active infection).

The median overall survival (OS) of aCML patients is between 12 and 25 months [2, 3]. In 37\%, aCML transforms into secondary acute myeloid leukemia (sAML), with a median time to transformation of 11.2 months. Unfavorable prognostic factors for the OS are an initial increased white blood cell count ( $>40 / \mathrm{nL})$, increased immature precursors in peripheral blood, female gender, and high patient age [3]. In a retrospective analysis of aCML patients after HSCT, $87 \%$ of the patients had a complete remission, $6.5 \%$ had a partial response, and $6.5 \%$ were non-responders. After 5 years, relapse-free survival (RFS) was $36 \%$ and mean OS $51 \%$. In the subgroup analysis, a young recipient age $(<45$ years $)$ and a low EBMT risk score (1-2 points) as well as stem cells from an unrelated HLA-compatible donor had a favorable effect on the 5-year OS [4]. Despite the low EBMT risk score, the patient achieved only a partial response on day +29 after transplantation. Certainly, the loss of time until HSCT due to severe infections 
and the need to reduce the toxicity of the conditioning regimen due to comorbidities and reduced general health condition were disadvantages. However, studies found no significant advantage in early HSCT within 6 months compared with transplantation between 6 and 12 months or more than 12 months after diagnosis [4].

One or two chromosomal aberrations (e.g., trisomy 8, del (20q), $-7 / 7 q$ or isochromosomes $17 q$ ) are found in $80 \%$ of patients [5]. Moleculargenetic changes are nonspecific. The most commonly affected genes $(>20 \%)$ are SETBP1, $A S X L 1, N / K-R A S, S R S F 2$, and TET2 and less frequently (< 10\%) CBL, CSFR3, JAK2, and ETNK1 [1]. The mutation in Splicing factor $3 B$ subunit 1 (SF3B1) gene, which was found in the patient, is most highly prevalent in MDS patients with ring sideroblasts (MDS-RS-SLD or MDS-RS-MLD) and is usually associated with a favorable prognosis [6]. Constitutional mutations in neurofibromin 1 (NF1) gene, which occurs in the RAS pathway, predispose patients to malignant myeloid disorders such as juvenile myelomonocytic leukemia (JMML), chronic myelomonocytic leukemia (CMML), and acute myeloid leukemia (AML), regardless of whether clinical signs of neurofibromatosis exist [7]. JMML is a pediatric myelodysplastic syndrome in which subclonal $N F 1$ mutations are detectable in fewer than $5 \%$ of cases [8]. In AML patients, mutations in NF1 gene are suggestive of an adverse prognostic impact [9]. Whether these two additional mutations in the SF3B1 and NF1 genes, as found in the patient, are driver mutations that adversely affect the aCML is conceivable but is currently still unclear.

Funding Information Open Access funding provided by Projekt DEAL.

\section{Compliance with ethical standards}

Conflict of interest The authors declare that they have no conflict of interest.

Informed consent Written informed consent was obtained from the patient for the publication of this case report and any accompanying images.

Open Access This article is licensed under a Creative Commons Attribution 4.0 International License, which permits use, sharing, adaptation, distribution and reproduction in any medium or format, as long as you give appropriate credit to the original author(s) and the source, provide a link to the Creative Commons licence, and indicate if changes were made. The images or other third party material in this article are included in the article's Creative Commons licence, unless indicated otherwise in a credit line to the material. If material is not included in the article's Creative Commons licence and your intended use is not permitted by statutory regulation or exceeds the permitted use, you will need to obtain permission directly from the copyright holder. To view a copy of this licence, visit http://creativecommons.org/licenses/by/4.0/.

\section{References}

1. Gotlib J (2017) How I treat atypical chronic myeloid leukemia. Blood 129(7):838-845. https://doi.org/10.1182/blood-2016-08693630

2. Gotlib J, Maxson JE, George TI, Tyner JW (2013) The new genetics of chronic neutrophilic leukemia and atypical CML: implications for diagnosis and treatment. Blood 122(10):1707-1711. https://doi.org/ 10.1182/blood-2013-05-500959

3. Wang SA, Hasserjian RP, Fox PS, Rogers HJ, Geyer JT, ChabotRichards D, Weinzierl E, Hatem J, Jaso J, Kanagal-Shamanna R, Stingo FC, Patel KP, Mehrotra M, Bueso-Ramos C, Young KH, Dinardo CD, Verstovsek S, Tiu RV, Bagg A, Hsi ED, Arber DA, Foucar K, Luthra R, Orazi A (2014) Atypical chronic myeloid leukemia is clinically distinct from unclassifiable myelodysplastic/ myeloproliferative neoplasms. Blood 123(17):2645-2651. https:// doi.org/10.1182/blood-2014-02-553800

4. Onida F, de Wreede LC, van Biezen A, Eikema DJ, Byrne JL, Iori AP, Schots R, Jungova A, Schetelig J, Finke J, Veelken H, Johansson JE, Craddock C, Stelljes M, Theobald M, Holler E, Schanz U, Schaap N, Bittenbring J, Olavarria E, Chalandon Y, Kroger N (2017) Allogeneic stem cell transplantation in patients with atypical chronic myeloid leukaemia: a retrospective study from the ChronicMalignancies Working Party of the European Society for Blood and Marrow Transplantation. Br J Haematol 177(5):759765. https://doi.org/10.1111/bjh.14619

5. Meggendorfer M, Bacher U, Alpermann T, Haferlach C, Kern W, Gambacorti-Passerini C, Haferlach T, Schnittger S (2013) SETBP1 mutations occur in $9 \%$ of MDS/MPN and in $4 \%$ of MPN cases and are strongly associated with atypical CML, monosomy 7 , isochromosome i(17)(q10), ASXL1 and CBL mutations. Leukemia 27(9): 1852-1860. https://doi.org/10.1038/leu.2013.133

6. Malcovati L, Karimi M, Papaemmanuil E, Ambaglio I, Jadersten M, Jansson M, Elena C, Galli A, Walldin G, Della Porta MG, RaaschouJensen K, Travaglino E, Kallenbach K, Pietra D, Ljungstrom V, Conte S, Boveri E, Invernizzi R, Rosenquist R, Campbell PJ, Cazzola M, Hellstrom Lindberg E (2015) SF3B1 mutation identifies a distinct subset of myelodysplastic syndrome with ring sideroblasts. Blood 126(2):233-241. https://doi.org/10.1182/blood-2015-03633537

7. Balgobind BV, Van Vlierberghe $P$, van den Ouweland AM, Beverloo HB, Terlouw-Kromosoeto JN, van Wering ER, Reinhardt D, Horstmann M, Kaspers GJ, Pieters R, Zwaan CM, Van den Heuvel-Eibrink MM, Meijerink JP (2008) Leukemia-associated NF1 inactivation in patients with pediatric T-ALL and AML lacking evidence for neurofibromatosis. Blood 111(8):4322-4328. https:// doi.org/10.1182/blood-2007-06-095075

8. Cazzola M, Della Porta MG, Malcovati L (2013) The genetic basis of myelodysplasia and its clinical relevance. Blood 122(25):40214034. https://doi.org/10.1182/blood-2013-09-381665

9. Eisfeld AK, Kohlschmidt J, Mrozek K, Mims A, Walker CJ, Blachly JS, Nicolet D, Orwick S, Maharry SE, Carroll AJ, Powell BL, Kolitz JE, Wang ES, Stone RM, de la Chapelle A, Byrd JC, Bloomfield CD (2018) NF1 mutations are recurrent in adult acute myeloid leukemia and confer poor outcome. Leukemia 32(12):2536-2545. https://doi. org/10.1038/s41375-018-0147-4

Publisher's note Springer Nature remains neutral with regard to jurisdictional claims in published maps and institutional affiliations. 